\title{
Estimating field-scale soil water dynamics at a heterogeneous site using multi-channel GPR
}

\author{
X. Pan ${ }^{1}{ }^{*}$, J. Zhang ${ }^{2}$, P. Huang ${ }^{2}$, and K. Roth $^{1}$ \\ ${ }^{1}$ Institute of Environmental Physics, Heidelberg University, Heidelberg, Germany \\ ${ }^{2}$ State Experimental Station of Agro-Ecosystem in Fengqiu, State Key Laboratory of Soil and Sustainable Agriculture, \\ Institute of Soil Science, Chinese Academy of Sciences, Nanjing, China \\ *now at: Global Institute for Water Security, University of Saskatchewan, Saskatoon, Canada
}

Correspondence to: X. Pan (xicai.pan@usask.ca)

Received: 19 May 2012 - Published in Hydrol. Earth Syst. Sci. Discuss.: 2 July 2012

Revised: 8 November 2012 - Accepted: 12 November 2012 - Published: 23 November 2012

\begin{abstract}
We explore the feasibility to quantify the fieldscale soil water dynamics through time series of GPR (ground-penetrating radar) measurements, which bridge the gap between point measurements and field measurements. Working on a $40 \mathrm{~m} \times 50 \mathrm{~m}$ area in a heterogeneous agricultural field, we obtain a time series of radargrams after a heavy rainfall event. The data are analysed to simultaneously yield (i) a three-dimensional representation of the subsurface architecture and (ii) the total soil water volume between the surface and a reflection boundary associated with the presence of paleo sand dunes or clay inclusions in a rather uniform sand matrix. We assess the precision and the accuracy of these quantities and conclude that the method is sensitive enough to capture the spatial structure of the changing soil water content in a three-dimensional heterogeneous soil during a short-duration infiltration event. While the sensitivity of the method needs to be improved, it already produced useful information to understand the observed patterns in crop height and it yielded insight into the dynamics of soil water content at this site including the effect of evaporation.
\end{abstract}

\section{Introduction}

As a key variable in the unsaturated zone, soil water content plays a crucial role in many environmental studies such as agriculture, hydrology and ecology. For instance, in the application of irrigation and drainage strategies, information of soil water content is of paramount importance to improve water use efficiency. However, understanding soil water dynamics at various scales is complicated due to the varying complexity in soil texture, soil layering and various environmental variables.

Soil water content measurements have made significant progress during the last few decades (Robinson et al., 2008). Point measurements can be obtained with the destructive gravimetric method and the less destructive neutron probe, time domain reflectometry (TDR) and capacitance probe methods. Measurements at catchment and continental scales may be obtained by remote sensing methods. The classical point scale measurement methods and large scale remote sensing methods cannot well capture the detailed behaviour of soil water dynamics at the field or catchment scale due to scale and temporal resolution issues (Robinson et al., 2008).

The emerging near-surface hydrogeophysical imaging techniques like ground- penetrating radar (GPR), electromagnetic induction (EMI) and electric resistivity tomography (ERT) offer promising potential to fill the gap of soil water sensing between the point and catchment scale (Robinson et al., 2008). The application of these technologies in hydrology, soil science and agriculture is ever increasing (e.g. Knight, 2001; Weihermüller et al., 2007; Robinson et al., 2009; Zhu et al., 2010; Wijewardana and Galagedara, 2010). Particularly, GPR has gained an increasing interest in various research fields. Reviews of GPR development and its advance for site characterisation and monitoring in hydrogeophysical studies can be found in Huisman et al. (2003a), Lambot et al. (2008), and Slob et al. (2010).

GPR ground wave techniques have been widely used for measuring surface soil water content (e.g. Huisman et al., 
2001, 2002; Grote et al., 2003; Galagedara et al., 2003, 2005; Grote et al., 2010). The field study by Huisman et al. (2003b) showed that the temporal development of spatial soil water content variation could be observed with the ground wave method at an accuracy comparable to TDR. Furthermore, an extensive field study by Steelman and Endres (2010) showed that near-surface soil water content variations over an annual cycle can be quantitatively captured by GPR ground wave measurements. However, the poor understanding of the propagation of the GPR signal in the radar-antenna-subsurface system hampers the application of GPR ground wave method for monitoring soil water dynamics in detail (Huisman et al., 2003a). An alternative to the traditional on-ground GPR is offered by off-ground GPR, which has a stronger focus on the surface reflection. For instance, the off-ground GPR system developed by Lambot et al. (2004, 2006) offers promising opportunities to measure surface soil water content at field conditions. Field studies demonstrate that with a proper radar system model this method provides high-resolution soil water content maps (e.g. Minet et al., 2012), even near-surface soil water content profiles (e.g. Minet et al., 2011).

For many applications, the water content throughout a soil profile is required in addition to the surface soil water content. This is in particular the case for all hydrologic applications. Borehole GPR can be used to map temporal soil water content variation with high resolution at larger depths (Galagedara et al., 2003; Kowalsky et al., 2005; Grote et al., 2010; Wijewardana and Galagedara, 2010), but limited at plot scale. For characterizing soil water flow at larger scale, the GPR reflection method has big advantages. Based on a known reflector depth, soil water content variation from point GPR measurements has been identified at laboratory (e.g. Loeffler and Bano, 2004) and at field sites (e.g. Wollschläger and Roth, 2005). Lunt et al. (2005) studied temporal variation of soil water content along profiles with known reflector depths at a heterogeneous site with GPR reflections. Furthermore, without known reflector depths, the studies by Bradford (2008) and Steelman and Endres (2012) using common mid-point (CMP) soundings or similar measurements demonstrate that spatio-temporal soil water content variations can be obtained from GPR reflections at field conditions. In particular, a multi-channel GPR setup such as that proposed by Gerhards et al. (2008) offers a quick and efficient imaging of soil water content and reflector depth. By optimizing the multi-channel GPR survey, Pan et al. (2012b) demonstrated that multi-channel GPR can be used to monitor seasonal soil water dynamics in a layered soil at field scale.

A number of studies reported the use of GPR for monitoring the soil water dynamics. For instance, monitoring wetting/drying fronts at natural and artificial conditions has been demonstrated by, for example, Binley et al. (2001), Stoffregen et al. (2002), Deiana et al. (2008), Haarder et al. (2011), and Mangel et al. (2012). Following this direction, the geophysical data are used to constrain unsaturated flow models. However, the accuracy of water-content estimates from GPR still challenges this as pointed out by Moysey (2010). One solution is using coupled inversion schemes that use rockphysics relationships to link the hydrologic process model with a geophysical instrument model (e.g. Kowalsky et al., 2005; Lambot et al., 2006; Looms et al., 2008). This is greatly facilitated by higher accuracy GPR measurements as presented here. The multi-channel GPR method allows to measure rather small changes of average or total water content within a layer during typical events.

Another issue for the field-scale soil hydrology model is soil heterogeneity. For specific soil architectures, soil water flow regimes may be different. Steelman and Endres (2012) demonstrated the application of GPR to characterise vertical soil water dynamics in multi-layered soils over a complete annual cycle. In addition, to image rainfall drainage over a 2-D area, Truss et al. (2007) have used a time-lapse GPR method and 2-D surveys to obtain the geometry of a preferential flow path and quantify changes in water content within a limestone site.

In this study, we demonstrated an application of the multichannel GPR method to quantify the field-scale soil water dynamics in an agricultural field. It demonstrates that the subsurface architecture required for accurate 3-D modelling of soil water dynamics can be obtained from the time lapse GPR radargrams and that the changes of the soil water content distribution can be determined with an accuracy that suffices to explore its impact on the spatial distribution of crop growth.

\section{Site description and measurements}

\subsection{Site description}

The study site is located in the vicinity of the Agroecological Experiment Station of the Chinese Academy of Sciences in Fengqiu County, near Daheigang at $35^{\circ} 2.1^{\prime} \mathrm{N}, 114^{\circ} 33.8^{\prime} \mathrm{E}$, Henan province, China. Soils in the Fengqiu County are dominated by Ochric Aquic Cambisol and Ustic Sandic Entisol (Li et al., 2007). The latter one accounts for less than $2 \%$ of land area. It usually appears in some areas along the Yellow River or ancient paths in the Yellow River flood plain. For instance, land surface at the study area is characterised by discontinuous stripped dunes. The study site was explored as farm land in the middle of 1980s. Since then, wheat, peanut and corn were planted with small farm machines.

At the study site, the surface soil texture consists of $82 \%$ sand, $6 \%$ clay and $12 \%$ silt. The water table was at a depth of about $1.7 \mathrm{~m}$, as inferred from drilling. Observations in two dug profiles (one is about $20 \mathrm{~m}$ away from the western border of the experimental plot, and the other one is about $25 \mathrm{~m}$ away from the southern border of the plot) shows that nearby ponding waters were at a depth of around $1.9 \mathrm{~m}$.

The area with underlying paleo-dunes is ideal for GPR exploration. Nearby the study site, Roth et al. (2004) 


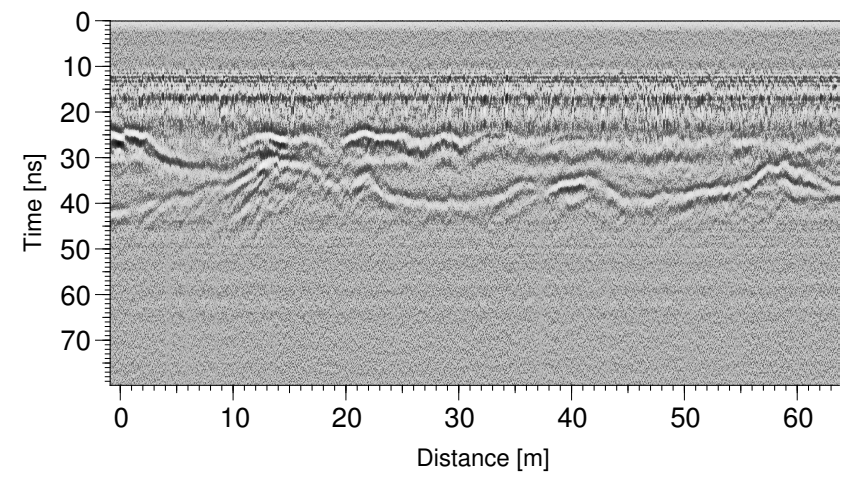

Fig. 1. Features of soil layering in the GPR radargram (p26 in Fig. 3).

demonstrated the applicability of exploring soil layers and water tables with GPR. At the study site, soil layering can be identified clearly in the radargrams (e.g. the reflection near $40 \mathrm{~ns}$ in Fig. 1) from GPR exploration. However, it is difficult to identify the structure below the shallow water table. This is attributed to the light salty water leading to high loss of electromagnetic wave transmission.

\subsection{Data acquisition}

An IDS (Ingegneria dei Sisteemi S.p.A., Italy) multichannel GPR system was used in this study. The setup with three different antenna separations, where $\mathrm{S} 1=\mathrm{S} 2=0.14 \mathrm{~m}$, $\mathrm{S} 3=1.94 \mathrm{~m}$ and $\mathrm{S} 4=1.66 \mathrm{~m}$, is shown in Fig. 2. This means that the GPR-derived soil water content stands for a mean value in the local volume within the maximum antenna separation above the reflector depth. Wheat at the study site was removed before the two-dimensional GPR survey. All the two-dimensional GPR surveys were conducted along prefixed parallel lines with a $1.5 \mathrm{~m}$ interval spacing (Fig. 3). Along the acquisition line GPR measured with a high resolution of $0.05 \mathrm{~m}$. The signal at each measurement points was recorded with a time window of $80 \mathrm{~ns}$ by stacking 12 scans and discretizing in 1024 samples. To get absolute travel times for all channels, time-zero calibration of the two channels crossing antenna boxes (S3, S4) was performed by carrying out wide-angle reflection-refraction (WARR) measurements in air, while the zero offsets of the two box-internal channels (S1, S2) were calibrated by directly picking the air wave wavelet. Before the rainfall event, the line p25 in Fig. 3 was measured with two antennas operating at a central frequency of $200 \mathrm{MHz}$ on 19 May 2011. Then five two-dimensional GPR surveys with two antennas operating at a central frequency of $400 \mathrm{MHz}$ were repeated on 22, 23, 25, 27, and 29 May 2011 after the heavy rainfall which followed ten days without any rainfalls (Fig. 4).

To assess reflector depth and soil water content from the multi-channel GPR measurements, some independent estimates were made by drilling and TDR measurements. Seven

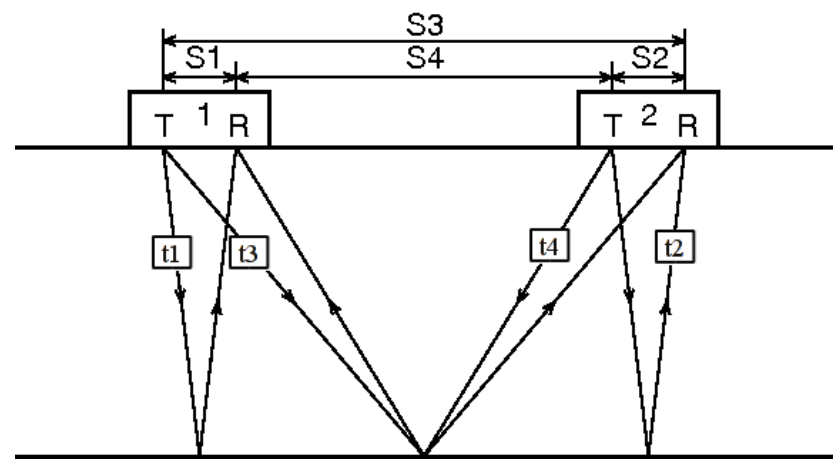

Fig. 2. Schematic of a four channel GPR setup.

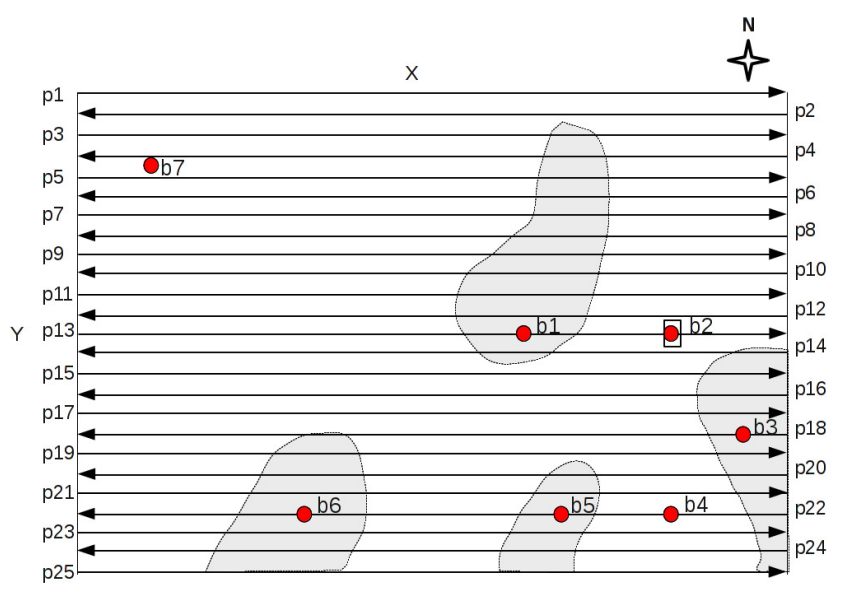

Fig. 3. A schematic of the field site with patterned crops $(45 \mathrm{~m} \times 36 \mathrm{~m})$ and the survey design. The grey areas indicate smaller wheat than that at the other area. Lateral lines and red circles are the route measurements of GPR survey and boreholes, respectively. The small box on p13 indicates the soil profile dug.

boreholes were drilled at different locations in Fig. 3. One soil profile at the position $40 \mathrm{~m}$ in the line p13 was dug after the survey on 29 May. Soil samples from each layers and nine soil water content measurements with a TDR probe were obtained in the soil profile.

\section{Methods}

\subsection{Estimates of reflector depth and soil water content}

The principle of the multi-channel GPR method has been shown in several studies (e.g. Gerhards et al., 2008; Wollschläger et al., 2010; Westermann et al., 2010). Its procedure has been presented in detail by Gerhards et al. (2008), and is only summarised briefly here. Travel times from the four channels in Fig. 2 were measured sequentially in one measurement. The basic travel time model is given as

$t\left(\epsilon_{c}, d\right)=\frac{\sqrt{\epsilon_{c}}}{c_{0}} \cos (\alpha) \sqrt{4 d^{2}+a^{2}}$, 

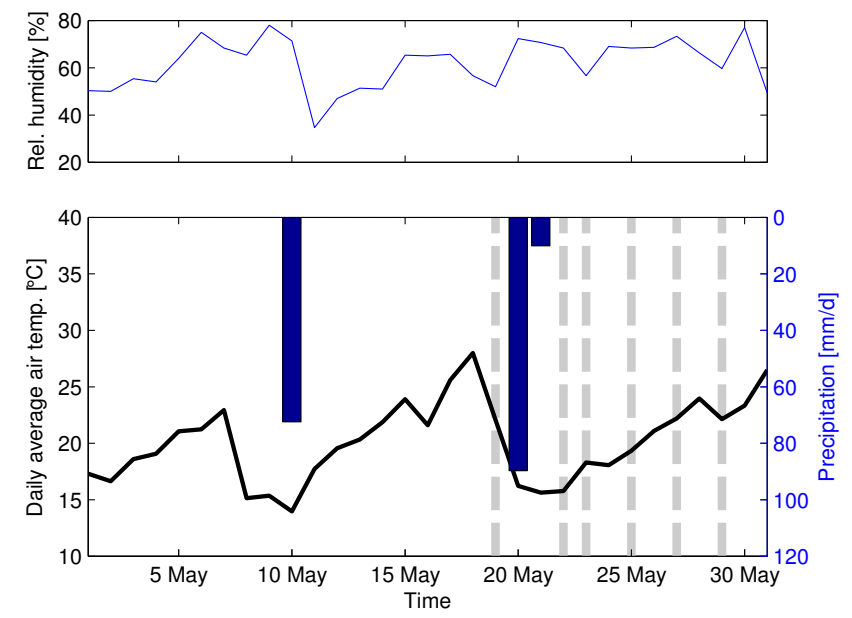

Fig. 4. Weather conditions nearby the study site in May 2011, and the times for GPR survey (dashed grey lines).

where $\epsilon_{c}[-]$ is the soil dielectric permittivity number, $c_{0}$ is the speed of light in vacuum $\left(0.3 \mathrm{~m} \mathrm{~ns}^{-1}\right), \alpha$ is the inclination angle of the reflector, and $d[\mathrm{~m}]$ is the reflector depth were conducted, and $a[\mathrm{~m}]$ is the antenna separation. Around each position they can be considered as a common reflection point from the available channels. Given the relation between the velocity of the electromagnetic wave in a low-loss soil and soil dielectric permittivity number $\epsilon_{c}, \epsilon_{c}$ and reflector depth $d$ $[\mathrm{m}]$ can be determined from all available travel times in a few common-midpoint (CMP) gathers with the object function $C\left(\epsilon_{c}, d, \alpha\right)$,

$C\left(\epsilon_{c}, d, \alpha\right)=\sum_{(n, k)}^{(N, K)}\left[t_{\text {model }}\left(x_{n}, a_{k}\right)-t_{\text {refl }}\left(x_{n}, a_{k}\right)\right]^{2}$,

where $N=3$ is the maximum number of measurement points around the centre position and $K=4$ is the maximum number of antenna separations in a CMP. For practical measurements, an array of small CMP gathers were collected at each trace along a survey line, accordingly the spatial distribution of reflector depth and soil dielectric permittivity can be obtained.

A petrophysical relationship of complex refractive index method was used to estimate volumetric soil water content (short as soil water content in the following context) $\theta$ $\left[\mathrm{m}^{3} \mathrm{~m}^{-3}\right]$ according to Roth et al. (1990)

$\sqrt{\epsilon_{c}}=\theta \sqrt{\epsilon_{\mathrm{w}}}+[1-\phi] \sqrt{\epsilon_{\mathrm{s}}}+[\phi-\theta] \sqrt{\epsilon_{\mathrm{a}}}$,

which quantitatively relates soil dielectric permittivity number $\epsilon_{c}$ to soil water content $\theta$, porosity $\phi[-]$ and relative dielectric permittivity numbers $\epsilon_{\mathrm{w}}, \epsilon_{\mathrm{a}}, \epsilon_{\mathrm{s}}$ of water, air, and soil matrix, respectively. In this paper we used $\epsilon_{\mathrm{w}}=80.2$, corresponding to $20^{\circ} \mathrm{C}$ (Kaatze, 1989), $\epsilon_{\mathrm{s}}=5.0, \epsilon_{\mathrm{a}}=1.0$, and $\phi=0.45$, which is an average of the whole studied layers according to the field soil sampling. In addition, Eq. (3) was also used for TDR evaluation with corresponding parameters based on the specific measured soil temperatures and soil porosities.

From the multi-channel GPR evaluation, the reflector depth $d$, the depth-averaged soil water content $\theta$ is simultaneously obtained. However, we are in favor of analyzing soil water dynamics, hence the total water volume $l_{\mathrm{w}}=d \times \theta$ $[\mathrm{m}]$ is also used in this study.

\subsection{Estimate of field evaporation}

The pan evaporation measurements were conducted at the Agroecological Experiment Station nearby the study site during the field campaign. The corresponding field evaporation $E\left[\mathrm{~m} \mathrm{~d}^{-1}\right]$ was approximately estimated by the empirical relationship between reference evaporation and pan evaporation from the equation (Allen et al., 1998)

$E=K_{\mathrm{p}} \times E_{\mathrm{p}}$,

where $E_{p}$ is the measured pan evaporation [m d6-1], and $K_{\mathrm{p}}$ is the empirical coefficient. Considering the bare surface with medium relative humidity (Fig. 4 ) and moderate wind speed at the study site, the coefficient $K_{\mathrm{p}}$ was set as 0.63 for the estimation according to the suggested determination of $E$ by Allen et al. (1998).

\subsection{Statistical analysis}

To investigate the stability of the measured reflector depth and the evolution of the spatial patterns of reflector depth and soil water content, we use the cross-correlation coefficient $\rho$ to quantify the correlation between two quantities $X$ and $Y$,

$$
\rho=\frac{\sum_{i} \sum_{j}\left(X_{i j}-\langle X\rangle\right)\left(Y_{i j}-\langle Y\rangle\right)}{\sqrt{\left[\sum_{i} \sum_{j}\left(X_{i j}-\langle X\rangle\right)^{2}\right]\left[\sum_{i} \sum_{j}\left(Y_{i j}-\langle Y\rangle\right)^{2}\right]}},
$$

where $i, j$ are the indices along and across the GPR lines, respectively, and $\langle X\rangle$ and $\langle Y\rangle$ are the corresponding mean values over all data (Snedecor and Cochran, 1980).

\section{Results and discussion}

\subsection{Spatio-temporal variation of measured quantities}

Combining the GPR exploration and borehole sampling information as listed in Table 1 from seven positions, we deduce that soil layering at the study site is generalised as coarse sand dunes covered by a top layer of loamy sand. In addition, two clay patches in the deep dune valleys appear above the dune interface at the section from 39 to $48 \mathrm{~m}$ in the lateral direction with high water content in Fig. 5a (area A). This is confirmed by a borehole sampling and a nearby soil 
Table 1. Observations of soil layering from borehole samplings (b1, b2, .., b7 shown in Fig. 3).

\begin{tabular}{ll}
\hline Borehole & Description of soil layering \\
\hline b1 & $0-1.12 \mathrm{~m}$ : loamy sand; $1.12-2 \mathrm{~m}$ : coarse sand, saturated below $1.80 \mathrm{~m}$ \\
b2 & $0-0.22 \mathrm{~m}$ : loamy sand; $0.22-0.28 \mathrm{~m}$ : clay; $0.28-0.76 \mathrm{~m}$ : loamy sand; \\
& $0.76-2.0 \mathrm{~m}$ : coarse sand, saturated below $1.82 \mathrm{~m}$ \\
b3 & $0-0.66 \mathrm{~m}$ : loamy sand; $0.66-2 \mathrm{~m}$ : coarse sand, saturated below $1.78 \mathrm{~m}$ \\
b4 & $0-0.68 \mathrm{~m}$ : loamy sand; $0.68-2 \mathrm{~m}$ : coarse sand, saturated below $1.79 \mathrm{~m}$ \\
b5 & $0-0.70 \mathrm{~m}$ : loamy sand; $0.70-2 \mathrm{~m}$ : coarse sand, saturated below $1.80 \mathrm{~m}$ \\
b6 & $0-0.69 \mathrm{~m}$ : loamy sand; $0.69-2 \mathrm{~m}$ : coarse sand, saturated below $1.80 \mathrm{~m}$ \\
b7 & $0-0.81 \mathrm{~m}$ : loamy sand; $0.81-2 \mathrm{~m}$ : coarse sand, saturated below $1.79 \mathrm{~m}$ \\
\hline
\end{tabular}

Table 2. Assessment on the stability of the estimated reflector depths via statistical analysis. $\Delta d$ is the average difference of the estimated reflector depths relative to the values measured on 22 May. $\rho$ is the correlation coefficient between the reflector depths measured at the given times.

\begin{tabular}{lrrrrrr}
\hline$\rho$ & $\Delta d[\mathrm{~m}]$ & 22 May & 23 May & 25 May & 27 May & 29 May \\
\hline 22 May & 0 & 1.000 & & & & \\
23 May & $-0.01 \pm 0.01$ & 0.995 & 1.000 & & & \\
25 May & $0.01 \pm 0.02$ & 0.991 & 0.990 & 1.000 & & \\
27 May & $0 \pm 0.02$ & 0.990 & 0.990 & 0.990 & 1.000 & \\
29 May & $0 \pm 0.02$ & 0.989 & 0.991 & 0.989 & 0.992 & 1.000 \\
\hline
\end{tabular}

profile (b2 with a box in Fig. 3). In the paper, we mainly focus on the field-scale soil water dynamics in the soil above the dune interface. Soil water content and total water volume in this layer were determined from multi-channel GPR measurements. The maps of soil water content and total water volume in Fig. 5 were produced with a grid $0.05 \mathrm{~m} \times 1.5 \mathrm{~m}$, which is the same as the spatial resolution of the measurements. Only a few occasional missing values (less than $3 \%$ of the total values) were linearly interpolated. Although the results would be influenced by this anisotropic data set, the major features are still clearly visible. The following maps were also produced with the same method.

\subsubsection{Stability of estimated soil layering}

Since reflector depth and soil water content are solved jointly in the multi-channel GPR evaluation, they are expected to be correlated. However, we found that the impact of this correlation on the accuracy of the estimated quantities can be reduced by optimizing the setup of the multichannel GPR as introduced by Pan et al. (2012b). Since the lower reflector is a boundary between soil layers, hence invariant in time, it allows to investigate the stability of the measured reflector depths in the time series measurements. First, we notice that the average difference $\Delta d$ between the depth estimates is very small, some $0.01 \mathrm{~m}$ (Table 2). Next, the correlation coefficients for the interpolated reflector depths for the five surveys were calculated. The results quantify the high similarity in the estimated reflector depths between all measurements with correlation coefficients ranging between 0.991 and 0.995 . Given this accuracy, we reconstructed the three-dimensional topography of the lower soil interface from averaging all five surveys (Fig. 6). The accuracy of the estimated reflector depths is assessed by the data of the seven boreholes. This yields an accuracy of $\pm 0.05 \mathrm{~m}$ (Fig. 7). We comment, however, that the number of boreholes is rather small and that part of the uncertainty stems from the boreholes.

\subsubsection{Assessing soil water content estimate}

Assessing the accuracy of the measured soil water content from the multi-channel GPR with the TDR measurements (Fig. 8) is fundamentally difficult. TDR measurements in the profile just stand for the soil water content at one position, while the GPR measurement yields an integral value for a much larger volume along the wave path. This is exacerbated by the presence of soil layers which further complicates the calculations for the TDR measurements. Finally, for the current study, there is only one TDR profile available, which yields a rather weak representativeness.

To estimate the average soil water content and the total water volume from the TDR measurements in the profile, soil water content (red dashed line in Fig. 8) was linearly interpolated within layers by presuming sharp layer boundaries. This profile consists of four different layers (i) loamy sand $(0-0.24 \mathrm{~m})$, (ii) clay $(0.24-0.35 \mathrm{~m})$, (iii) fine sand $(0.35-$ $0.78 \mathrm{~m}$ ) and (iv) coarse sand $(\geq 0.78 \mathrm{~m})$. Soil water contents were measured at depths of $0.09,0.17,0.31,0.4,0.55,0.7$, 0.79 and $0.9 \mathrm{~m}$. The measurements were conducted eight days after the rainfall event. By that time, the infiltration front had disappeared from the measured layers. Besides, the 

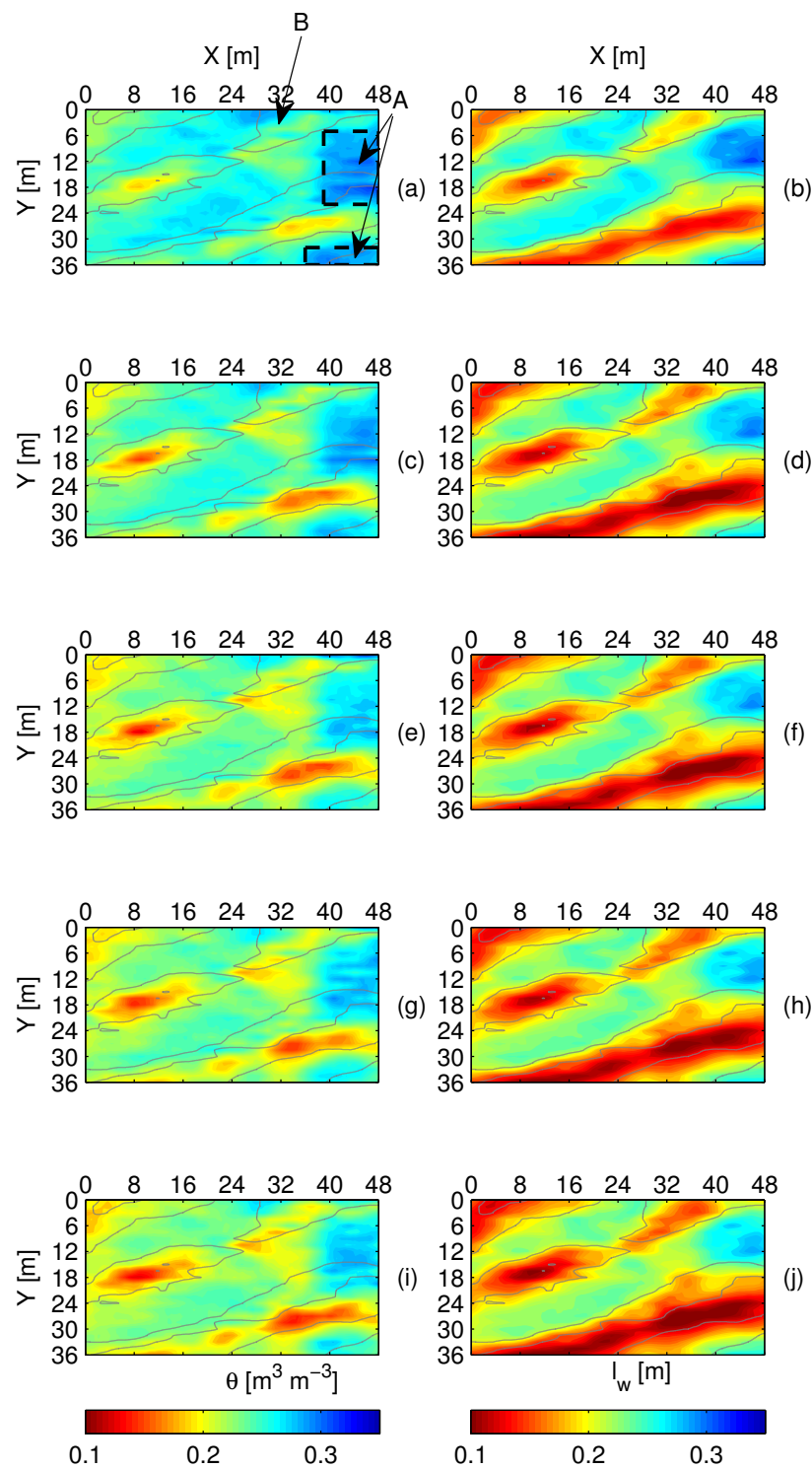

Fig. 5. Time-lapse images of depth-averaged soil water content $\theta$, and total water volume $l_{\mathrm{W}}$ between surface and the dune interface on 22, 23, 25, 27, 29 May 2011 (from top to bottom panels). Grey contour lines in all images represent the dune structure with a contour interval of $0.2 \mathrm{~m}$. Blocks $\mathrm{A}$ are the areas with clay inclusions over the dune structure, and the other area is marked as B.

soil water content in the clay layer is thought to be nearly constant due to its strong water retention. While the soil water content and the total water volume from the multichannel GPR measurement was calculated as the average values within the soil volume between antenna separations (around $2 \mathrm{~m}$ ) along the line p13.

Results show that the soil water content and the total water volume from TDR are $0.23 \pm 0.02 \mathrm{~m}^{3} \mathrm{~m}^{-3}$ and $0.18 \pm 0.01 \mathrm{~m}$, respectively, and the corresponding values from the multi-channel GPR are $0.27 \pm 0.01 \mathrm{~m}^{3} \mathrm{~m}^{-3}$ and $0.21 \pm 0.01 \mathrm{~m}$. There is a difference of $0.04 \mathrm{~m}^{3} \mathrm{~m}^{-3}$ in the

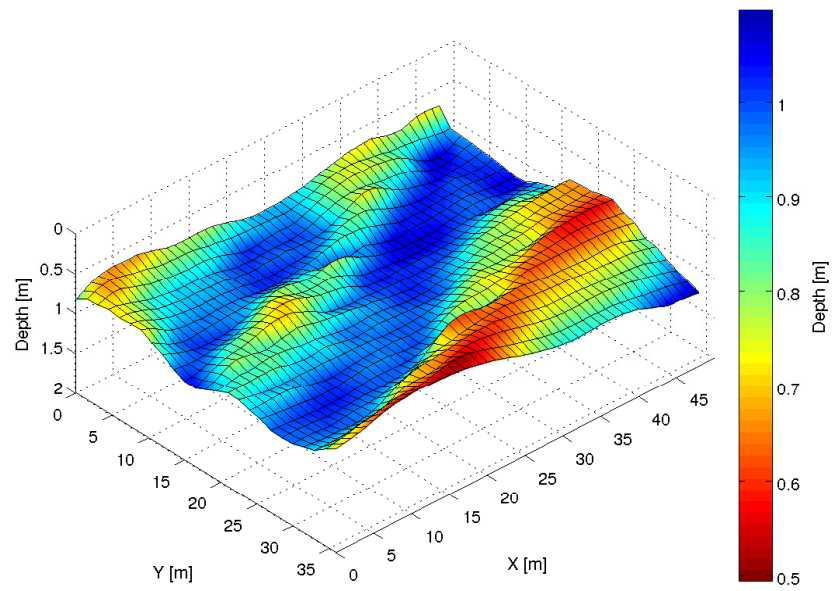

Fig. 6. Three dimensional reflector depth map for the dune-deposit structure using average data from a time series GPR measurements.

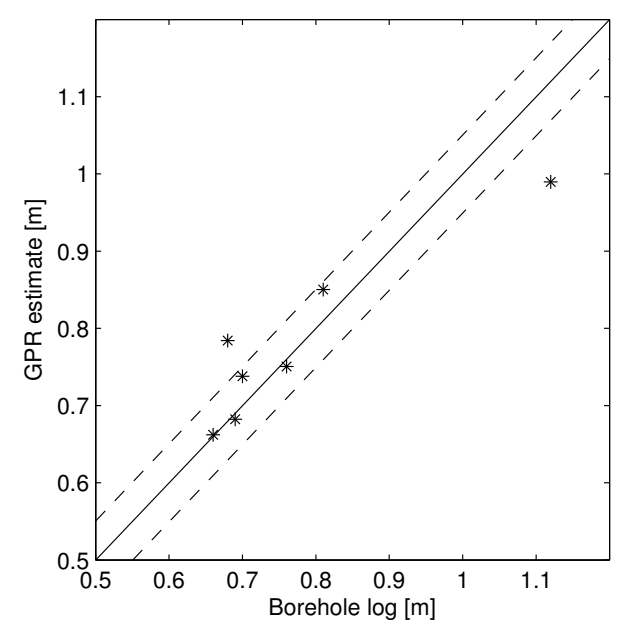

Fig. 7. Assessment on the accuracy of the multi-channel GPR for the estimates of reflector depths with borehole logs. Dashed lines stand for a standard deviation of $0.05 \mathrm{~m}$.

soil water content and $0.03 \mathrm{~m}$ in the total water volume. This difference is larger than the measurement precision of the two methods, hence warrants some discussion. First, both methods use the same underlying physical principle in comparable frequency ranges. In particular, the same petrophysical relation is used to calculate soil water content. Hence, we do not expect that the differences originate from that. A major difference is the measurement volume that TDR yields point values, essentially, representing a vertical extent of some $0.05 \mathrm{~m}$, whereas GPR produces true averages for the entire depth. We attribute the differences between TDR and GPR to this discrepancy in spatial coverage. Given the high accuracy of the reflector depth from the multi-channel GPR measurements, the soil water content jointly solved in the algorithm is expected to have a comparable accuracy. Thus we 

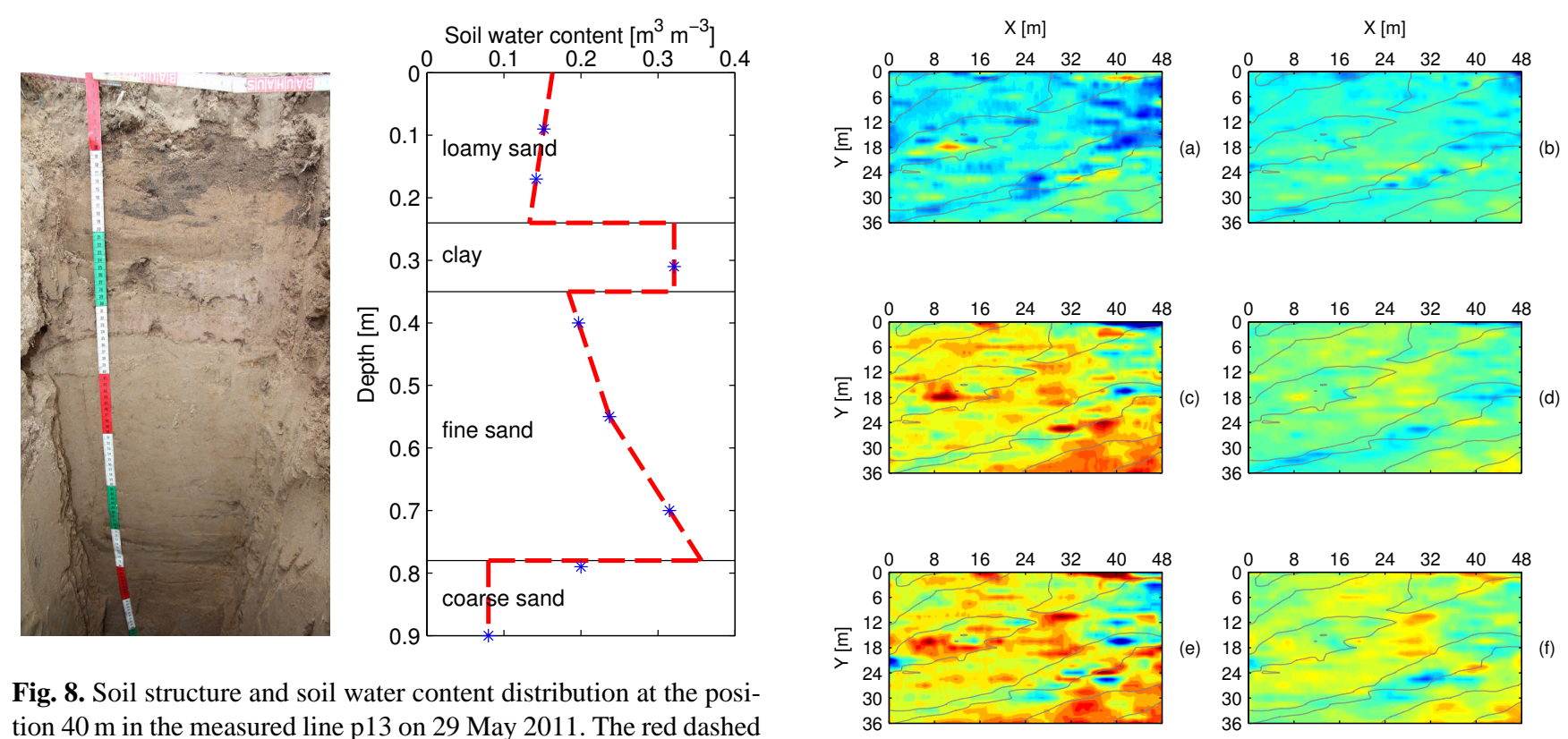

Fig. 8. Soil structure and soil water content distribution at the position $40 \mathrm{~m}$ in the measured line p13 on 29 May 2011. The red dashed line is the interpolated soil water content distribution from TDR measurements (blue stars).

trust the values from the multi-channel GPR measurements more than those from TDR measurements.

\subsubsection{Observation of field-scale soil water dynamics}

The differenced time-lapse maps of the soil water content and the total water volume compared with the measurement on 22 May are shown in Fig. 9. They clearly show that general decrease of the total water volume with time. While the averaged signal is pronounced, the fine spatial details are near to the resolution of the method and therefore not very clear visually. However, the differences of water volume changes at different areas are statistically significant at a p-level of 0.05 (Fig. 10d). We comment that with the signal near to the resolution limit, small measurement artifacts, most importantly the line structure from the GPR acquisition, become apparent. This graphical artifact does not affect our analysis, however, since the analysis is only based on point values, not on spatial relations between them. The amounts of the soil water content and the total water volume decrease in time, and some patterns also evolve at the same time, which may be related to the soil layering (contour lines). In the following, the field-scale soil water dynamics is investigated by analyzing the measured soil water content change $\Delta \theta$ and the total water volume change $\Delta l_{\mathrm{w}}$ at specific areas.

Soil water dynamics along the line p25, which was measured before and after the rainfall event from 19 to 29 May, is shown in Fig. 10a and b. Here it is important to note that $\Delta \theta$ and $\Delta l_{\mathrm{w}}$ are the expectations for the whole line. Thus, the error bar includes the information of the spatial changes of each quantity compared to the first measurement as well
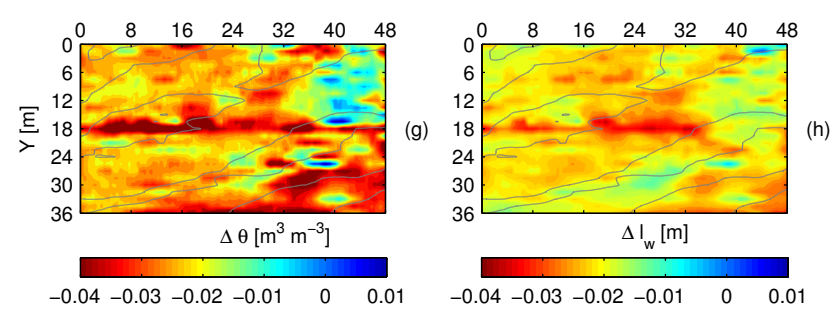

Fig. 9. Time-lapse images of measured soil water content change $\Delta \theta$ and total water volume change $\Delta l_{\mathrm{w}}$ between surface and the reflector at times 23, 25, 27, and 29 May 2011 (from top to bottom panels) relative to the values on 22 May. The contour lines are identical to those in Fig. 5.

as the information of the accuracy of the multi-channel GPR measurements. The increases of the averaged $\theta$ and $l_{\mathrm{w}}$ in the line $\mathrm{p} 25$ on 22 May reached $0.06 \mathrm{~m}^{3} \mathrm{~m}^{-3}$ and $0.04 \mathrm{~m}$, respectively, and then gradually decreased. To further investigate the spatially non-uniform change of water loss in time at the study site, soil water dynamics at three representative areas in Fig. 5a, the area A with dune valleys and clay inclusions and the area $\mathrm{B}$ with dune valleys (B1: $d \geq 1.0 \mathrm{~m}$ ) and ridges (B2: $d \leq 0.7 \mathrm{~m}$ ), are presented in Fig. 10c and d. The similar characteristics of soil water dynamics were found as those in the line $\mathrm{p} 25$. Moreover, the changes of $\theta$ and $l_{\mathrm{w}}$ slightly differed in time at the three areas. Particularly, the water loss in the valley was almost the same as those at the other areas from 22 to 23 May, and afterwards became larger.

In the multi-channel GPR evaluation, $\theta$ and $d$ are estimated jointly from the measured travel times, which are proportional to $l_{\mathrm{w}}$. The negative correlation between $\theta$ and $d$ originates in the relation $l_{\mathrm{w}}=\theta \times d$, where $l_{\mathrm{w}}$ is very well constrained from the measurement, because it is a first order 

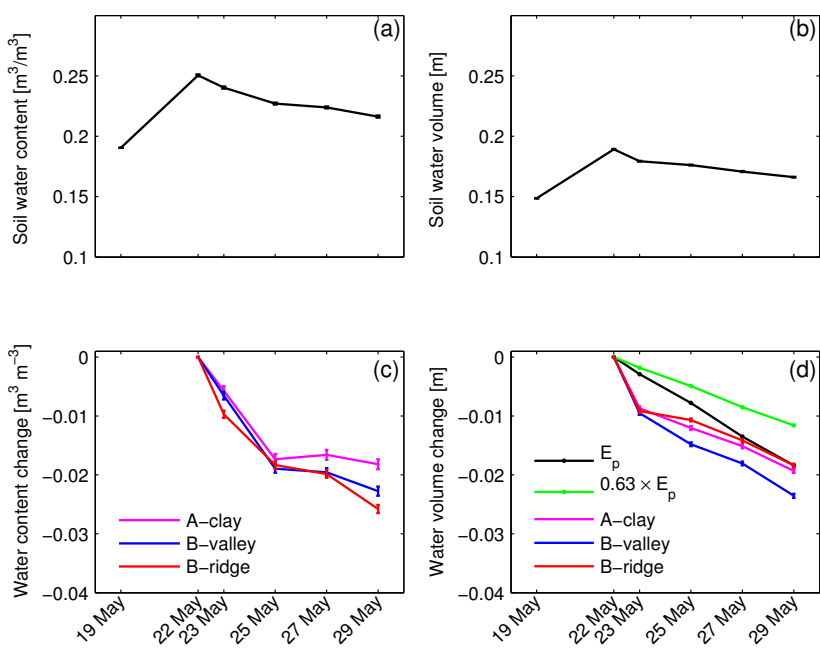

Fig. 10. Observations of the field-scale soil water dynamics at representative areas. (a) and (b) are the temporal changes of the averaged soil water content $\theta$ and the total water volume $l_{\mathrm{W}}$ in the profile $\mathrm{p} 25$ (Fig. 3) through the rainfall event, respectively. (c) and (d) are the 2-D average changes at three areas with different structures (A: clay patches, $\mathrm{B}$ : dune valley and dune ridge). Water loss by evaporation is given in (d), where $E_{\mathrm{p}}$ is pan evaporation, and $0.63 \times E_{\mathrm{p}}$ is an roughly estimation of the actual field evaporation.

estimate which can already be calculated from a single GPR channel. In contrast, the separation into $\theta$ and $d$ depends on the differences between multiple channels. Therefore, $l_{\mathrm{w}}$ would be expected to be more accurate than $\theta$ and $d$, particularly when significant deviations appear between them in the multi-channel GPR evaluation. As shown in Table 2, the measured reflector depth deviated slightly from 23 to 25 May. Thus, the measured soil water content would be expected to deviate oppositely. However, the deviation of the total water volume $l_{\mathrm{w}}$ is still very small due to the counteraction of the deviations of $\theta$ and $d$. The phenomenon in Fig. 10c and $\mathrm{d}$ shows that the soil water contents at the three areas decreased rapidly from 22 May to 25 May and afterwards decreased less rapidly or even remained constant, in contrast, the change of soil water volumes already slowed down one day earlier than that of $\theta$. This is attributed to noise in the multi-channel GPR analysis.

As a reference, the estimate of the actual evaporation at the study site is shown in Fig. 10d. Through extracting the contribution of the field evaporation from the total water loss, we deduce that weak bottom seepage still existed after 23 May. Considering the differences in the bottom seepages at the different areas, we deduce that the characteristics of the soil water dynamics are related to the soil layering and associated hydrological processes.

\subsection{Hydrological interpretation of vadose-zone processes at the study site}

Based on a time series of snapshots of the soil layering and the soil water content distribution with the multi-channel GPR at the study site, we propose the following explanation for the observed characteristics of the soil water dynamics: (i) after ten days of dry weather, soil water content distribution was at field capacity. (ii) During the heavy rainfall event, the infiltration increased the soil water content and with it the total water volume. (iii) Then soil water redistributed within the layer due to the dune structure with more soil water ending up in the valleys than at the ridges. (iv) When it comes to the loss of water from the observed layer, we have to distinguish two phases: a short initial phase with high water fluxes and a prolonged later phase with low fluxes. During the initial phase, the infiltrating water front that reaches the lower boundary leads to an approximately uniform and fast seepage. During the second phase, seepage is reduced significantly because of the decreasing water content, hence a rapidly decreasing hydraulic conductivity, and it is higher in the valleys where horizontal redistribution leads to a higher local water content than at the ridges. For both phases, evaporation is active, uniformly across the entire soil surface as analysed by Pan et al. (2012a). Finally, notice that loosing the same amount of water by evaporation would lead to a higher decrease of the volumetric water content over a ridge than over a valley.

\subsubsection{Exploration of the field-scale soil water dynamics}

The infiltration and redistribution of water in soils has been studied for a long time already, and it is well understood conceptually (e.g. Jury and Horton, 2004) with readily available numerical models to simulate it (e.g. Radcliffe and Šimůnek, 2010). The current challenge is to quantitatively cope with three-dimensional heterogeneous architectures at the field scale without the huge experimental effort required by traditional approaches. Multi-channel GPR offers a possibility to observe the dynamics of the water content distribution at with high spatial and temporal resolution. As we find in the following, this is also possible with a useful accuracy.

The proposed hydraulic dynamics - initial rapid seepage, uniform across the lower boundary, together with continued, constant, and uniform evaporation (Fig. 11) - is corroborated by the data (Fig. 10). Comparing ridges and valleys, shows that for the initial phase the total loss of water is the same (Fig. 10d) while the changes in the average volumetric water content are different (Fig. 10c). Looking at the later phase, when evaporation prevails, we first recall that the wheat was removed prior to the GPR measurements which left the ground surface nearly bare. From this, and considering the uniform soil properties near the surface, we expect the evaporation flux to be uniform. This again is corroborated by the measurements for the last two dates, 27 to 29 May, 


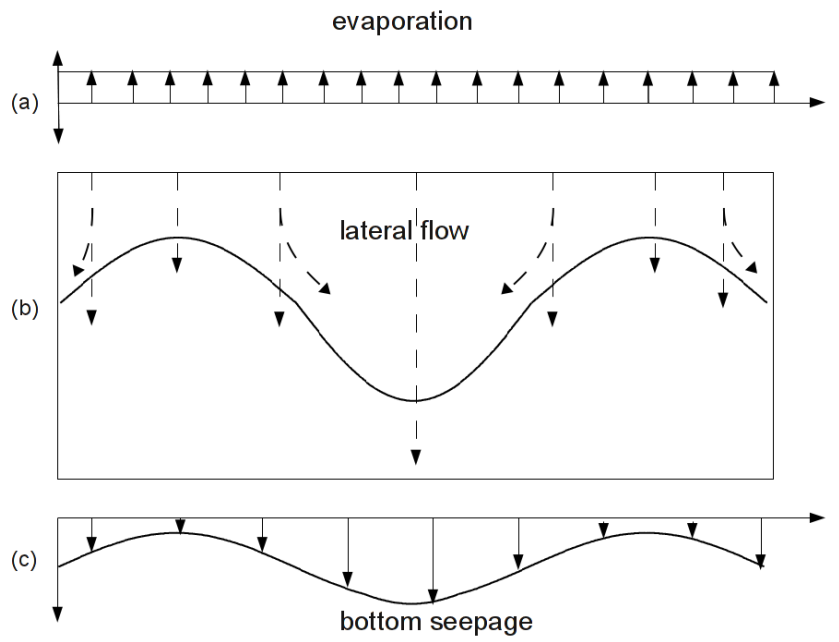

Fig. 11. Schematic of the proposed spatial soil water dynamics in a soil with dune-deposit structure. (a) Major processes at the surface; (b) soil water redistribution in the soil; (c) bottom seepage through the dune interface.

which show a comparable decrease of the total water volume above the ridges and the valleys. The changes in the average water content are correspondingly different. We explain the difference between the decrease curves for the later phase in Fig. $10 \mathrm{~d}$ by the additional seepage in the valleys which is caused by the horizontal redistribution of the water and by the longer flow distance with the associated delay.

In an attempt to further quantify these observations, the evolution of the cross-correlation coefficients (Eq. 5) between reflector depth $d$ on the one hand and average soil water content $\theta$ and water volume $l_{\mathrm{w}}$ on the other hand were calculated. Looking at the numbers in Table 3 reveals that none of the coefficients is particularly large. This is expected because (i) the accuracy of the multi-channel GPR measurements is at the lower end of the required accuracy for analyzing soil water dynamics and (ii) a low correlation between soil layering and soil water dynamics is expected because only part of the water flow will be redirected and there are heterogeneities like the clay inclusions. However, all except one of the coefficients are statistically significant at plevel 0.01 and hint at the underlying processes. On this basis, we further interpret some characteristics in Table 3. First, the temporal change of $\rho_{\mathrm{d} \theta}$ is different from $\rho_{\mathrm{dl}}$, in addition to their opposite signs. This would be related to some processes such as evaporation and drainage. For instance, a uniform evaporation leads to a negative correlation between $d$ and $\Delta \theta$, while a non-uniform bottom seepage caused by a time lag of the infiltration front or some lateral soil water redistribution leads to a positive correlation between $d$ and $\Delta l_{\mathrm{w}}$. These correlation coefficients change according to the corresponding processes, hence are indicators for them. For instance, the large negative $\rho_{\mathrm{d} \theta}$ and small positive $\rho_{\mathrm{dl}}$ on 23 May are interpreted to result from the quick infiltration,
Table 3. Changes of the relationship between soil layering and soil water dynamics at different mapping times relative to 22 May. $\rho_{\mathrm{d} \theta}$ and $\rho_{\mathrm{dl}}$ are the correlation coefficients between the reflector depth and the changes of soil water content and the total soil water volume, respectively. All values are significant at p-level 0.01 except the $\rho_{\mathrm{d} \theta}$ on 25 May.

\begin{tabular}{lrrrr}
\hline coeff. $\rho$ & 23 May & 25 May & 27 May & 29 May \\
\hline$\rho_{\mathrm{d} \theta}$ & -0.228 & -0.004 & -0.096 & -0.240 \\
$\rho_{\mathrm{dl}}$ & 0.059 & 0.380 & 0.279 & 0.301 \\
\hline
\end{tabular}

while the small negative $\rho_{\mathrm{d} \theta}$ and the large positive $\rho_{\mathrm{dl}}$ on 25 and 27 May hint at the non-uniform bottom seepage and the weak but increasing evaporation. On 29 May, the large negative $\rho_{\mathrm{d} \theta}$ and the large positive $\rho_{\mathrm{dl}}$ are thought to reflect the combined effects of the non-uniform bottom seepage and evaporation since 22 May.

\subsubsection{Influence of soil layering on the crops}

Since spatial soil water redistribution can influence the availability of soil water for agriculture, as well as the nutrient transport, it is more and more important for precision agriculture. At this study site, patterns of wheat can be found in Fig. 3. Since the wheat was planted with uniform fertilisation and management at the entire field, the surface pattern of wheat growth indicates the non-uniformly distributed soil characteristics and associated soil water dynamics. Due to the nearly homogeneous near-surface soil, its contribution to the spatial variation of soil water dynamics through infiltration and evaporation were thought to be negligible at the study site. Therefore, the patterned crops may be attributed to the structural heterogeneity.

From the experiments and previous discussion, we know that the dune structure and clay inclusions influenced the crop by redistributing soil water in space. As an example, the line p25 is specifically demonstrated in Fig. 12. Before the whole experiment the wheat pattern in the right part of the line p25 was similar to the wheat difference (red lines: P1 and P2) shown in Fig. 12a. While the soil layering mainly includes a deep continuous reflector (red line) and two small shallow reflectors marked with two dashed lines (P1 and P2) in Fig. 12b, which correspond to the wheat pattern in Fig. 12a. Through analyzing the changes of the soil water content $\Delta \theta$ and the total water volume $\Delta l_{\mathrm{w}}$ from 22 to 29 May relative to the measurement on 19 May in Fig. 12c and $\mathrm{d}$, we find that the evolution of $\Delta \theta$ and $\Delta l_{\mathrm{w}}$ patterns are related to the layering. On 22 May, $\Delta \theta$ and $\Delta l_{\mathrm{w}}$ were approximately uniform, while the water loss gradually increased from the ridge to the valley from 22 to 29 May. This is consistent with the previous result that the dune does play an important role in the soil water redistribution. However, the some near-surface structures could exert more impacts on the crop than the dune structure. For instance, compared to the 


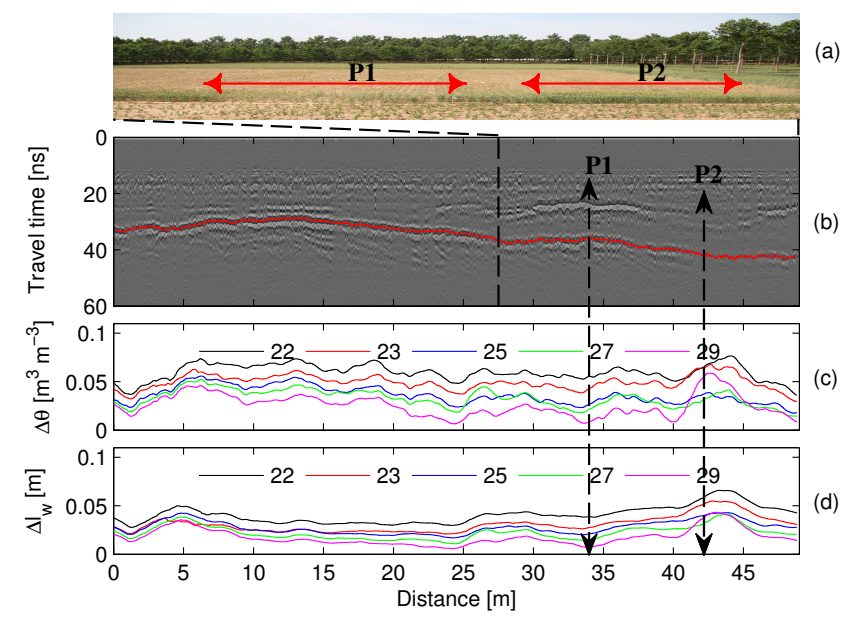

Fig. 12. The influence of soil layering on field-scale soil water dynamics and surface crops (e.g. the line p25 in Fig. 3). (a) Previous wheat feature in the line p 25 demonstrated by the wheat difference (lines: P1 and P2) nearby the line without cutting the wheat; (b) features of soil layering (red line: dune structure) in the radargram; (c) and (d) time lapse of the estimated soil water content change $\Delta \theta$ and the total water volume change $\Delta l_{\mathrm{w}}$ relative to the measurements on 19 May.

sandy interface at P1, the clay patch (P2) could facilitate the crop growth by retarding soil water infiltration. Besides, the clay inclusions are mainly located in the deep valley areas. In general, the dune structure correlates with the crop pattern shown in Fig. 3 by influencing soil water redistribution.

\section{Summary and conclusions}

We studied the soil water dynamics at a sandy site in the North China Plain with multi-channel GPR. Immediately before a heavy rainfall event a single GPR line was measured. After the rainfall, a short time series of two dimensional measurements was performed (days 22, 23, 25, 27, and 29 in May 2011). The data were analysed for reflector depth and depth-averaged soil water content.

The reflector apparently stems from a paleo-dune at a depth between 0.7 and $1.0 \mathrm{~m}$. Based on the measurements, the reflector depth was reconstructed with an estimated accuracy of $\pm 0.02 \mathrm{~m}$. The calculated distributions of soil water content for the different times showed a high precision and high coherence, such that we succeeded into subtracting them from each other and into deducing the field-scale soil water dynamics from this. The measurements could be explained by the following process chain: (i) the heavy rainfall increases the total water content significantly and the undulating lower layer boundary leads to some horizontal redistribution with more water ending up above the valley regions. (ii) Seepage occurs past the undulating boundary everywhere, at the ridges as well as in the valleys, hence the total amount of water is reduced with time. (iii) Due to the hydraulic characteristics, seepage decreases rather quickly with time after the rainfall event. (iv) A further water loss occurs by evaporation through the soil surface.

Considering the precision and the accuracy of the measured quantities and the deduced field-scale soil water dynamics in the heterogeneous soil during a short-duration infiltration event, we conclude that this method is sensitive enough to capture the spatial structure of the changing soil water content. We are, aware however, that despite statistical significance, the experimental support for this interpretation is not particularly strong. The accuracy of the multichannel GPR in determining the total amount of soil water is still limiting. Nevertheless, the kind of detailed information on the spatial processes is encouraging and warrants further development of the approach. This appears feasible with more frequent measurements to obtain the temporal change more accurately, and in particular by focusing the measurements to the early stage after a heavy rainfall event. We believe that this demonstration opens a door to high-resolution field-scale hydrological parametrisation and thus to much improved models.

Acknowledgements. We acknowledge Lingyun Zhou, Dan $\mathrm{He}$ and Zheng Zhang for field assistance. This study was funded in part by the Deutsche Forschungsgemeinschaft (DFG): project RO 1080/10-2, the National Natural Science Fundation of China (Grant No. 40571069) and the National Basic Research Program of China (Project No. 2011CB100506).

Edited by: M. Vanclooster

\section{References}

Allen, R. G., Pereira, L. S., Raes, D., and Smith, M.: Crop Evapotranspiration: guidelines for computing crop water requirements, FAO Irrigation and Drainage Paper No. 56, Rome, Italy, 1998.

Binley, A., Winship, P., Middleton, R., Pokar, M., and West, J.: High-resolution characterization of vadose zone dynamics using cross-borehole radar, Water Resour. Res., 37, 2639-2652, 2001.

Bradford, J. H.: Measuring water content heterogeneity using multifold GPR with reflection tomography, Vadose Zone J., 7, 184193, 2008.

Deiana, R., Cassiani, G., Villa, A., Bagliani, A., and Bruno, V.: Calibration of a vadose zone model using water injection monitored by GPR and electrical resistance tomography, Vadose Zone J., 7, 215-226, 2008.

Galagedara, L. W., Parkin, G., Redman, J., von Bertoldi, P., and Endres, A.: Field studies of the GPR ground wave method for estimating soil water content during irrigation and drainage, J. Hydrol., 301, 182-197, 2005.

Galagedara, L. W., Parkin, G. W., and Redman, J. D.: An analysis of the ground-penetrating radar direct ground wave method for soil water content measurement, Hydrol. Process., 17, 3615-3628, 2003. 
Gerhards, H., Wollschläger, U., Yu, Q., Schiwek, P., Pan, X., and Roth, K.: Continuous and simultaneous measurement of reflector depth and average soil-water content with multichannel ground-penetrating radar, Geophysics, 71, J15-J23, doi:10.1190/1.2943669, 2008.

Grote, K., Hubbard, S., and Rubin, Y.: Field-scale estimation of volumetric water content using ground-penetrating radar ground wave techniques, Water Resour. Res., 39, 1321, doi:10.1029/2003WR002045, 2003.

Grote, K., Anger, C., Kelly, B., Hubbard, S., and Rubin, Y.: Characterization of soil water content variability and soil texture using GPR groundwave techniques, J. Environ. Eng. Geoph., 15, 93110, doi:10.2113/JEEG15.3.93, 2010.

Haarder, E. B., Looms, M. C., Jensen, K. H., and Nielsen, L.: Visualizing unsaturated flow phenomena using high-resolution reflection ground penetrating radar, Vadose Zone J., 10, 84-97, 2011.

Huisman, J., Sperl, C., Bouten, W., and Verstraten, J.: Soil water content measurements at different scales: accuracy of time domain reflectometry and ground-penetrating radar, J. Hydrol., 245, 48-58, 2001.

Huisman, J. A., Snepvangers, J. J. J. C., Bouten, W., and Heuvelink, G. B. M.: Mapping spatial variation in surface soil water content: comparison of ground-penetrating radar and time domain reflectometry, J. Hydrol., 269, 194-207, 2002.

Huisman, J. A., Hubbard, J. D., Redman, J. D., and Annan, A. P.: Measuring soil water content with ground penetrating radar: a review, Vadose Zone J., 2, 476-491, 2003a.

Huisman, J. A., Snepvangers, J. J. J. C., Bouten, W., and Heuvelink, G. B. M.: Monitoring temporal development of spatial soil water content variation: comparison of ground penetrating radar and time domain reflectometry, Vadose Zone J., 2, 519-529, $2003 \mathrm{~b}$.

Jury, W. A. and Horton, R.: Soil Physics, 6th Edn., John Wiley \& Sons, New York, 2004.

Kaatze, U.: Complex permittivity of water as a function of frequency and temperature, J. Chem. Eng. Data, 34, 371-374, 1989.

Knight, R.: Ground penetrating radar for environmental applications, Annu. Rev. Earth Pl. Sc., 29, 229-255, 2001.

Kowalsky, M. B., Finsterle, S., Peterson, J., Hubbard, S., Rubin, Y., Majer, E., Ward, A., and Gee, G.: Estimation of field-scale soil hydraulic and dielectric parameters through joint inversion of GPR and hydrological data, Water Resour. Res., 41, W11425, doi:10.1029/2005WR004237, 2005.

Lambot, S., Slob, E. C., van den Bosch, I., Stockbroeckx, B., and Vanclooster, M.: Modeling of ground-penetrating radar for accurate characterization of subsurface electric properties, IEEE T. Geosci. Remote, 42, 2555-2568, 2004.

Lambot, S., Weihermüller, L., Huisman, J. A., Vereecken, H., Vanclooster, M., and Slob, E. C.: Analysis of airlaunched ground-penetrating radar techniques to measure the soil surface water content, Water Resour. Res., 42, W11403, doi:10.1029/2006WR005097, 2006.

Lambot, S., Slob, E., Vanclooster, M., Huisman, J. A., and Vereecken, H.: Hydrogeophysical techniques for site characterization and monitoring: recent advances in Ground-penetrating Radar, in: NATO Science for Peace and Security, edited by: Simeonov, L. and Sargsyan, V., Springer Netherlands, 183-202, doi:10.1007/978-1-4020-8257-3_15, 2008.
Li, Y., Chen, D., White, R., Zhu, A., and Zhang, J.: Estimating soil hydraulic properties of Fengqiu County soils in the North China Plain using pedo-transfer functions, Geoderma, 138, 261-271, doi:10.1016/j.geoderma.2006.11.018, 2007.

Loeffler, O. and Bano, M.: Ground penetrating radar measurements in a controlled vadose zone influence of the water content, Vadose Zone J., 3, 1082-1092, 2004.

Looms, M. C., Binley, A., Jensen, K. H., Nielsen, L., and Hansen, T. M.: Identifying unsaturated hydraulic parameters using an integrated data fusion approach on cross-borehole geophysical data, Vadose Zone J., 7, 238-248, 2008.

Lunt, I. A., Hubbard, S. S., and Rubin, Y.: Soil moisture content estimation using ground-penetrating radar reflection data, J. Hydrol., 307, 254-269, 2005.

Mangel, A. R., Moysey, S. M. J., Ryan, J. C., and Tarbutton, J. A.: Multi-offset ground-penetrating radar imaging of a labscale infiltration test, Hydrol. Earth Syst. Sci., 16, 4009-4022, doi:10.5194/hess-16-4009-2012, 2012.

Minet, J., Wahyudi, A., Bogaert, P., Vanclooster, M., and Lambot, S.: Mapping shallow soil moisture profiles at the field scale using full-waveform inversion of ground penetrating radar data, Geoderma, 161, 225-237, doi:10.1016/j.geoderma.2010.12.023, 2011.

Minet, J., Bogaert, P., Vanclooster, M., and Lambot, S.: Validation of ground penetrating radar full-waveform inversion for field scale soil moisture mapping, J. Hydrol., 424-425, 112-123, doi:10.1016/j.jhydrol.2011.12.034, 2012.

Moysey, S. M. J.: Hydrologic trajectories in transient groundpenetrating-radar reflection data, Geophysics, 75, WA211WA219, 2010.

Pan, X., Klenk, P., Roth, K., Zhang, J., Huang, P., and He, D.: Multi-channel GPR to assess the influence of shallow structural heterogeneity on spatio-temporal variations of nearsurface soil water content, in: Ground Penetrating Radar (GPR), 14th International Conference 2012, Shanghai, 659-663, doi:10.1109/ICGPR.2012.6254944, 2012a.

Pan, X., Wollschläger, U., Gerhards, H., and Roth, K.: Optimization of multi-channel ground-penetrating radar for quantifying field-scale soil water dynamics, J. Appl. Geophys., 82, 101-109, doi:10.1016/j.jappgeo.2012.02.007, 2012b.

Radcliffe, D. and Šimůnek, J.: Soil Physics with HYDRUS: Modeling and Applications, CRC Press/Taylor \& Francis, Boca Raton, FL, 2010.

Robinson, D. A., Campbell, C. S., Hopmans, J. W., Hornbuckle, B. K., Jones, S. B., Knight, R., Ogden, F., Selker, J., and Wendroth, O.: Soil moisture measurement for ecological and hydrological watershed-scale observatories: a review, Vadose Zone J., 7, 358-389, 2008.

Robinson, D. A., Lebron, I., Kocar, B., Phan, K., Sampson, M., Crook, N., and Fendorf, S.: Time-lapse geophysical imaging of soil moisture dynamics in tropical deltaic soils: an aid to interpreting hydrological and geochemical processes, Water Resour. Res., 45, W00D32, doi:10.1029/2008WR006984, 2009.

Roth, K., Schulin, R., Flühler, H., and Attinger, W.: Calibration of time domain reflectometry for water content measurement using a composite dielectric approach, Water Resour. Res., 26, 22672273, 1990. 
Roth, K., Wollschläger, U., Cheng, Z., and Zhang, J.: Exploring soil layers and water tables with ground-penetrating radar, Pedosphere, 14, 273-282, 2004.

Slob, E., Sato, M., and Olhoeft, G.: Surface and borehole groundpenetrating-radar developments, Geophysics, 75, A103-A120, doi:10.1190/1.3480619, 2010.

Snedecor, G. W. and Cochran, W. G.: Statistical Methods, Iowa State University Press, Ames, Iowa, 1980.

Steelman, C. M. and Endres, A. L.: An examination of direct ground wave soil moisture monitoring over an annual cycle of soil conditions, Water Resour. Res., 46, W11533, doi:10.1029/2009WR008815, 2010.

Steelman, C. M. and Endres, A. L.: Assessing vertical soil moisture dynamics using multi-frequency GPR common-midpoint soundings, J. Hydrol., 436-437, 51-66, 2012.

Stoffregen, H., Zenker, T., and Wessolek, G.: Accuracy of soil water content measurements using ground penetrating radar: comparison of ground penetrating radar and lysimeter data, J. Hydrol., 267, 201-206, 2002.

Truss, S., Grasmueck, M., Vega, S., and Viggiano, D. A.: Imaging rainfall drainage within the Miami oolitic limestone using high-resolution time-lapse ground-penetrating radar, Water Resour. Res., 43, W03405, doi:10.1029/2005WR004395, 2007.
Weihermüller, L., Huisman, J., Lambot, S., Herbst, M., and Vereecken, H.: Mapping the spatial variation of soil water content at the field scale with different ground penetrating radar techniques, J. Hydrol., 340, 205-216, 2007.

Westermann, S., Wollschläger, U., and Boike, J.: Monitoring of active layer dynamics at a permafrost site on Svalbard using multichannel ground-penetrating radar, The Cryosphere, 4, 475-487, doi:10.5194/tc-4-475-2010, 2010.

Wijewardana, Y. and Galagedara, L.: Estimation of spatio-temporal variability of soil water content in agricultural fields with ground penetrating radar, J. Hydrol., 391, 24-33, 2010.

Wollschläger, U. and Roth, K.: Estimation of temporal changes of volumetric soil water content from ground penetrating radar reflections, Subsur. Sens. Technol. Appl., 6, 207-218, 2005.

Wollschläger, U., Gerhards, H., Yu, Q., and Roth, K.: Multi-channel ground-penetrating radar to explore spatial variations in thaw depth and moisture content in the active layer of a permafrost site, The Cryosphere, 4, 269-283, doi:10.5194/tc-4-269-2010, 2010.

Zhu, Q., Lin, H., and Doolittle, J.: Repeated electromagnetic induction surveys for determining subsurface hydrologic dynamics in an agricultural landscape, Soil Sci. Soc. Am. J., 74, 1750-1762, 2010 . 